\title{
Hymenal findings in women referred to Fars legal medicine center examination unit, southwest of Iran
}

\author{
Arya Hedjazi', Mohammad Zarenezhad ${ }^{1,2}$, Sharareh Roshanzamir ${ }^{3}$, Saeed Gholamzadeh ${ }^{1}$, \\ Maryam Valee ${ }^{1}$, Alireza Shaghaghian ${ }^{4}$, Amin Hosseinzadeh ${ }^{1}$, Fattah Jafarizadeh ${ }^{5}$, Mahmoud \\ Montazeri $^{1}$, Masoud Ghadipasha ${ }^{1, *}$ \\ ${ }^{1}$ Legal Medicine Research Center, Legal Medicine Organization, Tehran, Iran \\ ${ }^{2}$ Gastroenterohepatology Research Center, Shiraz University of Medical Sciences, Shiraz, Iran \\ ${ }^{3}$ Burn Research Center, Shiraz University of Medical Sciences, Shiraz, Iran \\ ${ }^{4}$ Student Research Centre, International branch, Shiraz University of Medical Sciences, Shiraz, Iran \\ ${ }^{5}$ Criminal law and criminology, Legal Medicine Research Center, Legal Medicine Organization, Tehran, Iran
}

\section{Email address:}

m_ghadipasha@yahoo.com (M. Ghadipasha),zarenezhad@hotmail.com (M. Zarenezhad)

\section{To cite this article:}

Arya Hedjazi, Mohammad Zarenezhad, Sharareh Roshanzamir, Saeed Gholamzadeh, Maryam Valee, Alireza Shaghaghian, Amin Hosseinzadeh, Fattah Jafarizadeh, Mahmoud Montazeri, Masoud Ghadipasha. Hymenal Findings in Women referred to Fars Legal Medicine Center Examination Unit, Southwest of Iran. Journal of Gynecology and Obstetrics. Vol. 2, No. 2, 2014, pp. 12-15. doi: 10.11648/j.jgo.20140202.11

\begin{abstract}
Background: Normal hymenal appearance in adolescents is still not well-documented. Aim: In the present paper, we describe the hymenal findings in a population of Persian women. Materials and methods: This descriptive study was performed in Legal Medicine Center of Fars Province during 2008-2011. The questionnaire was used for collecting data according to the patients' interviews and hymenal physical examinations. SPSS 16 software was used for analyzing the data. P-values less than 0.05 were considered significant. Results: A total of 1'323 women were included. The average age of our study samples was $21.78 \pm 2.98$ years. Most of the hymens were non elastic $(53.58 \%)$, followed closely by elastic hymens (46.17\%). A $86.99 \%$ of the hymens were annular with smooth and continuous rim. The majority of our study's population $(80.23 \%)$ was referred to us beyond three weeks of their suspected hymenal injury. Regarding hymen's health condition, $57.71 \%$ were intact, while $42.25 \%$ were injured. There was significant association between the patients' age and duration between hymenal injury and examination $(\mathrm{P}-$ Value $=0.023)$ and hymen's health condition $(\mathrm{P}-\mathrm{Value}=0.001)$. Conclusion: The results highlighted the importance of training experienced physicians and midwives from both medical and legal aspects.
\end{abstract}

Keywords: Hymen, Physical Examination, Forensic Medicine, Shiraz, Iran

\section{Introduction}

The hymenal membrane consists of fibrous connective tissue with low vascular supply $[1,2]$. This membrane is located behind the vaginal entrance and attaches to the vaginal wall so that it may rupture during intercourse. Adolescents may have intercourse and an intact hymen $[3,4]$.

Diagnosis of the healthy hymen is possible through gynecological examinations by trained physicians or experienced midwives [5].

\section{Indications for Hymenal Examination within Iranian Society}

The genital examination is not a routine part of health maintenance assessment in premarital girls within Iranian society. However, evaluation of the hymen because of some personal/cultural reasons, or for suspected sexual abuse which is referred from relevant authorities such as legal and criminal courts, has been addressed extensively in the recent years [5-7].

Personal/cultural reasons for hymenal examination, which are done without referring from courts, include: 
A) Pre-marriage examination is performed for (upon the girl's request): 1) virginity certificate for presenting to her spouse before marriage, and 2) virginity certificate after trauma to the perineum.

B) Post-marriage examination is performed in cases that have no bleeding after the first sexual intercourse. In these cases, the examining physician registers type of the hymen membrane in the examination certificate accurately.

Legal/criminal reasons for hymenal examination include:

A) Raped women.

B) In Iranian marriage the issue of Mahrieh (dowry) which is based on "Islamic law" is very important. This is the sum value of cash and jewelry which is payable to the bride. If a divorced woman was virgin, she would take onehalf of her Mahrieh.[6]

To our knowledge, a great body of the published literature describes the anatomical differences between normal and injured hymenal appearance in adolescents [8$15,18]$. In this regard, Berenson et al. founded that the hymenal examination of the abused child is rarely different from that of the non-abused child [13]. Saint-Martin et al. performed a study on 756 cases of sexual assault. They concluded that the presence of genital trauma was not associated with conviction [14]. In the present paper, we described hymenal characteristics on physical examination in our study population. We attempted to improve our understanding of different anatomical types of hymen membrane and their frequency among population and therefore helping medical examiners to distinguish normal hymens from injured ones.

\section{Materials and Methods}

This descriptive-analytic study was performed to evaluate the hymenal findings. The study population was all women who were referred to Female Examination Unit of Fars Legal Medicine Center, Southwest of Iran, for hymen membrane examination during the period from March 20, 2008 to April 19, 2011. A total of 1,323 cases were eligible for our study from the women who were referred to Female Examination Unit for hymen membrane examination during the study period.

All the patients were interviewed to determine the patient's age, educational level, time and the cause of refer. Then the patients were examined with labial traction in a supine frog-leg position by two physicians with special training in forensic medicine. Physical examination data include anatomical type of the hymen, hymen's health condition (intact or injured), time interval between hymenal injury and examination, type and anatomical site of physical injury.

A questionnaire was used for collecting data. Forensic medicine specialists, at the Female Examination Unit of Fars Legal Medicine Center, made this questionnaire and filled it according to the patients' interviews and physical examinations. The study was explained to the patients who then gave their written informed consent. Any patient who did not sign the informed consent was excluded from the study and the examination was consensual in all cases. Helsinki's moral principles were considered for keeping human identity, prestige and medical secrets.

SPSS version 16.0.2 - April 2008. statistical software for Windows was used for analyzing the data. Paired t-tests and Chi-square (Steel and Torrie, 1990) were used to evaluate for statistical significance. P-values less than 0.05 were considered significant.

\section{Results}

A total of 1,323 patients were eligible for our study from the women who were referred to Female Examination Unit for hymen membrane examination during the study period.

The average age of our study samples was $21.78 \pm 2.98$ years; the youngest patient was 2.5 years old and the oldest was 53 years old. The most prevalent age group was 16-20 years old.

In terms of educational level (Table 1), the majority of the patients were diploma and above-diploma (46.7 and 28.4 percent, respectively), while the minority of the patients was of illiterate and doctorate degrees (1.1 and 3.1 percent, respectively).

Table 1. The distribution of educational levels in women who were referred to Fars Legal Medicine Center for hymen membrane examination during 2008-2011.

\begin{tabular}{ll}
\hline Level of education & Proportion $(\%)$ \\
\hline Illiterate & 1.05 \\
Under-diploma & 6.72 \\
Diploma & 46.71 \\
Above-diploma & 28.42 \\
Bachelor of Science/Master of science & 14.05 \\
Doctorate & 3.05 \\
Total & 100 \\
\hline
\end{tabular}

Table 2. The distribution of study population based on the reasons for which were referred among women who were referred to Fars Legal Medicine Center for hymen membrane examination during 2008-2011.

\begin{tabular}{ll}
\hline Reasons for which were referred & Proportion (\%) \\
\hline Personal/cultural & 20.6 \\
Legal & 58.9 \\
Criminal (Raped women) & 19.9 \\
State Welfare Organization of Fars & 0.6 \\
Total & 100 \\
\hline
\end{tabular}

A $1042(78.8 \%)$ of the patients were referred from both legal and criminal courts, $273(20.6 \%)$ patients referred due to personal reasons and eight patients $(0.6 \%)$ were referred from the State Welfare Organization of Fars. The reasons for these examinations are presented in details within Table (2).

According to hymen membrane examination, most of the hymens were non elastic $(53.6 \%)$, followed closely by elastic hymens (46.4\%). Three patients had imperforate hymens.

From the anatomical standpoint, $1150(86.1 \%)$ of the 
hymens were annular with smooth and continuous rim, 80 $(6.1 \%)$ of cases were crescentic, $32(2.4 \%)$ of cases were annular/septate, $32(2.4 \%)$ of cases were hymenal tags, 13 $(1.0 \%)$ of the cases were crescentic/septate, 10 patients had cribriform hymen, four patients had annular with fimbriated rim hymen and two patient had not hymen membrane due to anatomical anomalies.

Regarding hymen's health condition, $763(57.7 \%)$ of the hymens were intact, while $560(42.3 \%)$ hymens were injured. Of all 560 injured hymens, we found that 248 (44.3\%) of them dilated and penetrated, 163 (29.1\%) with laceration and $149(26.1 \%)$ with abrasion. Three patients had no hymen membrane. The majority of the females with injured hymens $(80.2 \%)$ were referred to us beyond three weeks of their suspected hymenal injury.

Abrasion and laceration of the hymen were most frequent among elastic annular hymens with smooth/continuous rim and non elastic annular hymens with smooth/continuous rim, respectively $(76.6,60.4$ percent, respectively).

Of all 263 patients who were referred for the assessment of sexual assault, $112(42.6 \%)$ patients had intact hymens while $151(57.4 \%)$ patients had injuries in their hymen which were classified into dilated/penetrated hymens $(56$, $37.1 \%)$, lacerations $(53,35.1 \%)$ and abrasions $(42,27.9 \%)$.

The most prevalent age group, the patients who were referred for the sexual assault assessment was 16-20 years old $(42.4 \%)$, followed by $21-25$ years old $(31.6 \%), \geq 26$ years old $(21.9 \%)$ and less than 16 years old $(4.5 \%)$.

Evaluation of the hymenal findings revealed significant association of the patients' age with duration between hymenal injury and examination (P-Value $=0.023)$ in addition to hymen's health condition (direct association, PValue $=0.001$ )

\section{Discussion}

In the current study, most of the hymens were annular/non elastic that is in harmony with the study of Towfighi et al. from Iran [11]. Also, annular/elastic hymens comprise relatively high proportion of all cases. Hymenal elasticity is referred to the hymen's resistance and recovery from distortion of shape $[16,18]$ and is an important issue in our practice due to cultural context of Iranian society. This is critically important while examining the patients, because elastic membranes may remain intact even after sexual intercourse due to consistency and elasticity of their tissue. Therefore, these cases have no bleeding after their first intercourse and refer to us for virginity certificate $[6,7$, $18]$.

As reported by previous medico-legal studies concerning sexual assaults cases, our findings confirm that adolescents and young adults constituted most of the patients who were referred for the sexual assault evaluation $[10-12,14]$.

Adolescents and young adults are at a unique transitional stage of physical, psychological, cognitive and social human development which makes them more vulnerable to sex related crimes or even attempted suicide as a result of undergoing hymen examination against their will [17]. Training programs should be improved via organizing training workshops at the schools or media to adequately train all adolescents and young adults about the risks of uncontrolled sexual contacts.

The majority of our patients were referred to us after three weeks of an incidence of possible hymenal injury which is consistent with the earlier study performed in Iran [11]. However, our results are not compatible with the study of Grossim et al. [12] from France. This long time interval could be explained partly as: a) the fear of disgrace after telling their problem, b) cultural and religious environment of the country which makes the premarital sexual relations unacceptable for women within Iranian society. Further studies should be done to understand the real causes of this long duration, c) insufficient awareness regarding the proper time for examination.

The results of this study offer the insight to different anatomical types of hymen membrane and their frequency among population. In addition, it helps medical examiners to distinguish healthy hymens from injured ones during a gynecological examination and finally become more confident in their observations and documentation of hymen examination.

\section{Limitations of the Study}

Like other manuscripts, our study has some limitations. First, interviewing which might make the participants less comfortable to answer the questions. Second, because this study is the first one in our environment, we have a number of limitations related to the study design. Future studies should be focused on evaluating Tanner stage, distribution of children, adolescents and adults based on the reason for referring, kind of hymen and hymenal health condition.

\section{Acknowledgements}

This work was funded by the Legal Medicine Research Center, Legal Medicine Organization, Shiraz, Iran and This article has been driven out of the theses of Alireza Shaghaghian, medical student of international branch, Shiraz university of medical sciences, Shiraz, Iran, with respective number of 10609 . The authors declare that they have no conflict of interest.

\section{References}

[1] Cruikshank SH, Davies J. Anatomy of the female genital tract. In: Scott JR, DiSaia PJ, Hammond CB, Spellacy WN. Danforth's Obstetrics and Gynecology. 9th edition. Lippincott Williams \& Wilkins; 2003. P. 9.

[2] Tanagho E, Nguyen HT. Embryology of the genitourinary system. In: Tanagho E, McAnich JW, editors. Smith's General Urology. 17th edition. San Francisco: McGraw-Hill; 2008. P. 27. 
[3] Biggs M, Stermac LE, Divinsky M. Genital injuries following sexual assault of women with and without prior sexual intercourse experience. CMAJ. 1998; 159(1):33-7.

[4] Jones JS, Rossman L, Hartman M, Alexander CC. Anogenital injuries in adolescents after consensual sexual intercourse. Acad Emerg Med. 2003 Dec; 10(12):1378-83.

[5] Akhlaghi M, Afshar M, Barooni S, Taghadosinejad F, Towfighi H, Ghorbani M. Essential of forensic medicine and toxicology. 1nd ed. Tehran University Of Medical Science: 2004; 8-266 [In Persian].

[6] Gudarzi F. Forensic medicine for students of law. 1st ed. Tehran: Judicial Police Publication;1989. P. 12-87 [In Persian].

[7] Gudarzi F. The diagnosis of sexual intercourse "defloration or non-defloration" in dilated hymens. Scientific Journal of Forensic Medicine 2000; 18(5):61-4 [In Persian].

[8] Towfighi H, Nematollahi Z, Mosavipour F. Determination of incidence and characteristic of sexual offences in women referred to Tehran legal medicine organization (central branch) during the second semester of 1999. 2002; 25(7):4-6 [In Persian].

[9] Hinds A, Baskin LS. Child sexual abuse: what the urologist needs to know. J Urol 1999;162(2):516-23.

[10] Edgardh K, von Krogh G, Ormstad K. Adolescent girls investigated for sexual abuse: history, physical findings and legal outcome. Forensic Sci Int 1999; 104(1):1-15.

[11] Towfighi H, Vaezi S. Epidemiologic survey about situation of hymen in persons referred to examination part of Tehran legal medicine center during summer and autumn of 2007. Scientific Journal of Forensic Medicine 2009; 15:92-5 [In Persian].

[12] Grossim C, siille I, Grandmaison G, Banasr A, Brion F, Durigon M, et at. Analysis of 418 cases of sexual assault. Forensic Sci Int 2003; 131(2-3):125-30.

[13] Berenson AB, Chacko MR, Wiemann CM, Mishaw CO, Friedrich WN, Grady JJ. A case-control study of anatomic changes resulting from sexual abuse. Am J Obstet Gynecol $2000 ; 182(4): 820-31$.

[14] Saint-Martin P, Bouyssy M, Jacquet A, O'Byrne P. [Sexual assault: medicolegal findings and legal outcomes (analysis of 756 cases)]. J Gynecol Obstet Biol Reprod (Paris). 2007; 36(6):588-94 [Used Abstract].

[15] Berenson AB, Heger AH, Hayes JM, Bailey RK, Emans SJ. Appearance of the hymen in prepubertal girls. Pediatrics 1992; 89(3):387-94.

[16] Pokorny SF, Murphy JG, Preminger MK. Circumferential hymen elasticity. A marker of physiologic maturity. J Reprod Med. 1998; 43:943-8.

[17] Gursoy E, Vural G. Nurses' and midwives' views on approaches to hymen examination. Nurs Ethics. 2003; 10(5):485-96.

[18] Hedjazi A, Zarenezhad M, ShaykhAzadi A, Valie M. Epidemiologic study of hymen situation in persons referred to examination part of shiraz legal medicine organization. Yafteh. 2012; 14 (1) $1: 31-37$ [In Persian]. 